\title{
PRAKTIK HIDUP BERKESADARAN UNTUK ANAK USIA DINI
}

\author{
Waluyo \\ STABN Sriwijaya \\ sadarsetiapsaat76@gmail.com
}

\begin{abstract}
The issue of this article focuses on the conflicts and violence that concern many parties as it involves children. The involvement of children in world conflict is a contribution and a large role of adults around them, especially parents and families. Children who are raised with violence will give birth to a violent generation of ambiguous ambitions that can create chaos and even future physical warfare. Informal, non-formal, and even formal education is still less than optimal in generating a loving generation and tends to concentrate on competitive performance with minimal mastery of social and emotional skills. This article aims to provide a comprehensive description of life-conscious practices that are applied to early childhood in accordance with moral development and character formation of children.

This method of study uses a syntesize checklist consisting of preliminary, advanced, and final systesis; taking into account elements of text, context, and discourse. The object of this study is ideas about the conscious practice of various literature sources, especially its application that can be used for the age of the children. The validity of the study is based on a confirmability that reflects the objectivity of the study.

The results of the study show that: (a) the form of awareness practices that can be applied to early childhood, namely: living together, breathing, sitting meditation, eating together, resting, noble silence, hugging meditation, meditation, taking refuge, taking care of anger, and coming home; (b) the integration of life-conscious practices for moral development includes: coming home, relativistic hedonism (resting), sitting meditation, noble silence, hugging meditation, maintaining social norms and authority (eating together, tea meditation), orientation of self-esteem with the social environment (taking refuge, taking care of anger), and the universal principle (living together, breathing); and (c) the integration of conscious forms of living practice can each lead to the formation of character that includes three components: moral knowing (conscious, knowing, moral, self-knowing, decisions, perspectives), moral feeling (selfcontrol, empathy, loving truth, ), and moral action (want, custom, competent).
\end{abstract}

Keywords: Early childhood, life conscious.

\begin{abstract}
Abstrak
Permasalahan artikel ini berfokus pada konflik dan kekerasan yang menjadi perhatian banyak pihak karena melibatkan anak-anak. Keterlibatan anak-anak dalam konflik dunia merupakan andil dan peran besar dari orang dewasa di sekelilingnya, terutama orangtua dan keluarga. Anak-anak yang dibesarkan dengan kekerasan akan melahirkan generasi yang beringas penuh ambisi keangkaramurkaan yang dapat menimbulkan kekacauan bahkan peperangan fisik di masa mendatang. Pendidikan informal, nonformal, bahkan formal dirasa masih kurang optimal dalam menghasilkan generasi yang memiliki sifat penuh kasih dan cenderung konsen pada kinerja kompetitif minim penguasaan keterampilan sosial dan emosional. Artikel ini
\end{abstract}


bertujuan untuk memberikan deskripsi komprehensif praktik hidup berkesadaran yang diterapkan untuk anak usia dini yang sesuai dengan perkembangan moral dan pembentukan karakter anak.

Metode kajian ini menggunakan syntesize checklist yang terdiri dari sistesis pendahuluan, lanjutan, dan akhir; dengan mempertimbangkan unsur teks, konteks, dan wacana. Objek material kajian ini adalah ide-ide mengenai praktik hidup berkesadaran dari berbagai sumber pustaka, terutama penerapannya yang dapat digunakan untuk usia anak-anak. Keabsahan kajian didasarkan pada konfirmabilitas yang mencerminkan objektivitas kajian.

Hasil kajian menunjukkan bahwa: (a) bentuk praktik kesadaran yang dapat diterapkan pada anak usia dini yaitu: living together, breathing, sitting meditation, eating together, resting, noble silence, hugging meditation, tea meditation, taking refuge, taking care of anger, dan coming home; (b) integrasi praktik hidup berkesadaran untuk perkembangan moral meliputi: orientasi terhadap kepatuhan dan hukum (coming home), relativistic hedonism (resting), orientasi mengenai anak yang baik (sitting meditation, noble silence, hugging meditation), mempertahankan norma-norma sosial dan otoritas (eating together, tea meditation), orientasi pada perjanjian dirinya dengan lingkungan sosial (taking refuge, taking care of anger), dan prinsip universal (living together, breathing); dan (c) integrasi bentuk praktik hidup berkesadaran masing-masing dapat mengarah pada pembentukan karakter mencakup tiga komponen, yaitu moral knowing (sadar, tahu, alasan moral, tahu diri, keputusan, perspektif), moral feeling (kontrol diri, empati, mencintai kebenaran, rendah hati), dan moral action (ingin, kebiasaan, kompeten).

Kata kunci: Anak usia dini, hidup berkesadaran.

\section{Pendahuluan}

Dunia yang penuh konflik dan kekerasan menjadi perhatian banyak pihak karena melibatkan anak-anak. Radikalisasi dan konflik dengan melibatkan anak-anak menjadi perhatian dan kecaman tokoh-tokoh besar dari seluruh negara di dunia. Keterlibatan anak-anak dalam konflik dunia merupakan andil dan peran besar dari orang dewasa di sekelilingnya, terutama orangtua dan keluarga. Anak-anak yang dibesarkan dengan kekerasan akan melahirkan generasi yang beringas penuh ambisi keangkaramurkaan yang dapat menimbulkan kekacauan bahkan peperangan fisik di masa mendatang. Pendidikan informal, nonformal, bahkan formal dirasa masih kurang optimal dalam menghasilkan generasi yang memiliki sifat penuh kasih dan cenderung konsen pada kinerja kompetitif minim penguasaan keterampilan sosial dan emosional. Krisis generasi yang penuh 
kasih dan antikekerasan akan menjadi ancaman besar dunia jika usaha-usaha tidak dilakukan secara optimal untuk pencegahannya.

Radikalisme akhir-akhir ini tidak hanya menyasar orang dewasa, namun melibatkan anak-anak. Contoh kasus terjadi di Medan, di mana teror terjadi pada level anak-anak dan pelakunya adalah anak di bawah umur (https://nasional.tempo.co/read/846217/cegah-anak-anak-terpapar-

radikalisme-kpai-gandeng-bnpt). Dari sumber yang sama, Komisi Perlindungan Anak Indonesia (KPAI) menyebutkan data bahwa anak yang menjadi korban radikalisme meningkat sebesar $42 \%$ dalam kurun waktu satu tahun, yaitu 2015 ke 2016, dari 180 kasus meningkat menjadi 256 kasus. Hal ini menunjukkan kondisi yang sangat mengkhawatirkan, mengingat anakanak adalah harapan masa depan suatu bangsa. Jika anak-anak sudah terlibat dalam kelompok-kelompok radikal dan teroris, maka masa depan bangsa akan rusak dan tidak memiliki arah yang jelas.

Praktik hidup berkesadaran menjadi tren baru pada masa modern sekarang ini. Pada dasarnya, hidup berkesadaran sebagai bagian dari ajaran Buddha merupakan praktik sederhana yang dapat diterapkan dalam kehidupan sehari secara meditatif dan alami untuk menumbuhkan batin yang damai dalam diri seseorang, di mana hal tersebut dapat membawa dampak pada lingkungan sekitarnya. Jika seseorang membawa aura dan pesan damai dalam dirinya, niscaya lingkungan sosial di sekitarnya akan merasakan dampaknya, sehingga dapat digunakan sebagai gerakan sosial untuk memberi kontribusi pada masyarakat yang semakin sibuk penuh ketegangan. Manfaat praktik hidup berkesadaran dapat mengurangi stres dalam menjalani kehidupan, meminimalkan kecemasan, lebih peduli pada lingkungan dan kehidupan, penuh damai, antikekerasan penuh kasih, dan berdampak sosial pada gerakan massal yang menjadi ciri khas generasi sekarang.

Anak-anak usia dini memiliki potensi murni yang bebas dari pemanfaatan kepentingan orang dewasa. Orang dewasa yang sadar akan tugasnya dalam menumbuhkan kebaikan hati dan kedamaian pada diri anakanak menempuh usaha dan memberi peluang untuk mengembangkan batin secara optimal. Proses ini sejalan dengan usaha mengembangkan anak usia dini pada tahap perkembangan nilai moral dan agama. Nilai moral dan 
agama pada anak usia dini yang berkembang dapat ditempuh dengan menjalankan praktik hidup berkesadaran yang khas untuk anak-anak. Praktik hidup berkesadaran yang dibiasakan sejak dini akan membawa manfaat besar sebagai pribadi unggul berkesadaran pada kehidupannya kelak di masa dewasa.

Praktik hidup berkesadaran digagas dan dipraktikkan oleh Thich Nhat Hanh dan komunitasnya Plum Village yang berbasis di Prancis. Kegiatan ini dengan berbagai variasinya telah menyebar ke seluruh dunia dan memiliki komunitas hampir di setiap negara. Pada dasarnya praktik hidup berkesadaran adalah melaksanakan kegiatan sehari-hari dengan meditatif (http://thichnhathanhfoundation.org/be-mindful-in-daily-life/). Aktivitas sehari-hari memiliki fungsi yang berguna untuk menumbuhkan kedamaian dan kehalusan budi yang bermanfaat untuk masa depan anak-anak. Aktivitas keseharian dilakukan secara meditatif untuk memudahkan konsentrasi anakanak maupun mengenal secara mendalam interkoneksi antarkomponen hingga sesuatu dapat berlangsung.

Praktik hidup berkesadaran dapat diterapkan pada anak-anak dan digunakan sebagai alat pendidikan untuk meningkatkan atensi, kebijaksanaan emosional maupun kognitif, penyadaran serta koordinasi jasmani, serta keterampilan yang berhubungan antarpribadi (Hanh, 2016: ix). Praktik hidup berkesadaran pada usia anak-anak lebih didominasi oleh aktivitas keseharian yang dekat dengan dunia anak-anak. Kebijaksanaan emosional sebagai hasil proses yang panjang merupakan latihan berkelanjutan yang dimulai dari usia dini. Kebiasaan yang dilakukan sejak usia dini memberikan pemahaman mendalam bagi anak-anak untuk bekal hidup di masa mendatang. Bekal ini digunakan untuk berdampingan secara harmoni dengan komunitas lain, melintasi etnis, budaya, maupun negara.

Standar tingkat pencapaian perkembangan anak usia dini merupakan kriteria tentang kemampuan yang dicapai anak pada seluruh aspek perkembangan dan pertumbuhan, mencakup aspek nilai agama dan moral, fisik-motorik, kognitif, bahasa, sosial-emosional, serta seni. Aspek nilai agama dan moral memiliki peran strategis dalam membentuk generasi yang siap menghadapi tantangan global di masa depan. Pengembangan nilai 
keagamaan dan moral bagi anak usia dini terarah pada pemberian upaya perlakuan tertentu dalam bentuk pembelajaran kepada anak melalui aktivitas mereka sehari-hari. Aktivitas permainan, bergaul, bersosialisasi, bercakapcakap, berdialog, menjawab atau merespons pertanyaan, makan, mengandung aspek ajaran moral dan nilai-nilai keagamaan.

Pendidikan agama Buddha memberikan pengajaran yang cenderung mengedepankan aspek perkembangan nilai moral dan agama sebagaimana dikemukakan oleh Smith (2013: 25-26) sebagai berikut: (a) pendidikan agama Buddha bertujuan untuk memberikan kontribusi pada pengembangan spiritual setiap anak yang datang ke sekolah, dengan menghargai dan merefleksi program pendidikan yang diselenggarakan oleh sekolah, (b) penekanan pendidikan agama Buddha adalah toleransi, kerja sama, dan tanpa kekerasan, bertujuan untuk mengembangkan pengetahuan, keterampilan, dan nilai-nilai yang diperlukan dalam diri anak-anak sebagai bagian dari anggota masyarakat yang harmoni dan cinta damai, (c) setiap pengajaran pendidikan agama Buddha didasarkan pada ajaran Buddha tanpa memandang sekte apapun, dan (d) pembelajaran pendidikan agama Buddha menggunakan pendekatan active learning yang berbasis pada pengalaman anak. Aspek perkembangan nilai moral dan agama menjadi tujuan utama dalam setiap program yang disusun atau diselenggarakan oleh pengelola pendidikan agama Buddha, baik pada tingkat sekolah maupun kelas. Program-program ini tentu saja harus sejalan dengan keinginan dan kebutuhan orangtua anak didik. Hal ini membawa implikasi adanya dialog dan kerja sama antara pihak sekolah dan guru dengan orangtua anak. Dialog ini akan menghasilkan sistem ideal yang menjadi kesepakatan kedua pihak, kemudian secara bersama-sama mencapai tujuan pembelajaran yang ditetapkan sesuai peran yang melekat.

Kohlberg (Cyrus T. Lalompoh \& Kartini Ester Lalompoh, 2017: 55) membagi perkembangan moral menjadi enam tahapan yang terbagi menjadi tiga tingkat. Tingkatan perkembangan moral memiliki enam tahap pencapaian yang masing-masing tahap memiliki ciri khusus yang mencerminkan perilaku yang muncul pada tahapan tersebut. Tabel berikut menjelaskan tahapan dan tingkatan dengan ciri-ciri khusus mengenai perkembangan moral anak. 
Tabel 1

Perkembangan Moral Menurut Kohlberg

\begin{tabular}{|l|l|l|}
\hline \multicolumn{1}{|c|}{ Tingkat } & \multicolumn{1}{|c|}{ Tahapan } & \multicolumn{1}{c|}{ Ciri Khusus } \\
\hline $\begin{array}{l}\text { Tingkat I } \\
\text { Prakonvensional }\end{array}$ & $\begin{array}{l}\text { Tahap 1 } \\
\text { Orientasi terhadap } \\
\text { kepatuhan dan hukuman } \\
\text { Tahap 2 } \\
\text { Relativistic hedonism }\end{array}$ & $\begin{array}{l}\text { Patuh agar tidak dihukum. } \\
\text { Ada faktor pribadi yang relatif dan } \\
\text { prinsip kesenangan. }\end{array}$ \\
\hline $\begin{array}{l}\text { Tahap II } \\
\text { Konvensional }\end{array}$ & $\begin{array}{l}\text { Tahap 3 } \\
\text { Orientasi mengenai anak } \\
\text { yang baik. }\end{array}$ & $\begin{array}{l}\text { Agar menjadi anak yang baik, } \\
\text { perbuatannya harus diterima oleh } \\
\text { masyarakat. }\end{array}$ \\
& $\begin{array}{l}\text { Tahap 4 } \\
\text { Mempertahankan norma } \\
\text { sosial dan otoritas }\end{array}$ & $\begin{array}{l}\text { Menyadari kewajibannya untuk } \\
\text { ikut melaksanakan norma-norma } \\
\text { yang ada dan mempertahankan } \\
\text { pentingnya ada norma-norma. }\end{array}$ \\
\hline $\begin{array}{l}\text { Tahap III } \\
\text { Pascakonvensional }\end{array}$ & $\begin{array}{l}\text { Tahap 5 } \\
\text { Orientasi terhadap } \\
\text { perjanjian antara dirinya } \\
\text { dengan lingkungan } \\
\text { sosial }\end{array}$ & $\begin{array}{l}\text { Perjanjian antara dirinya dengan } \\
\text { lingkungan sosial dan berbuat baik } \\
\text { agar diperlakukan baik. }\end{array}$ \\
& $\begin{array}{l}\text { Tahap 6 } \\
\text { Prinsip universal }\end{array}$ & $\begin{array}{l}\text { Berkembangnya normal etik (kata } \\
\text { hati) untuk menentukan perbuatan } \\
\text { moral dengan prinsip universal. }\end{array}$ \\
\hline
\end{tabular}

\section{Metode}

Analisis pembahasan kajian ini menggunakan syntesize checklist yang terdiri dari sistesis pendahuluan, lanjutan, dan akhir; dengan mempertimbangkan unsur teks, konteks, dan wacana (Mestika Zed, 2008: 71, 76-77). Unsur teks tidak sekadar merujuk pada kata-kata yang tercetak atau tertulis, tetapi semua jenis komunikasi, ucapan, musik, gambar, efek suara, citra dan sebagainya mengenai objek kajian yaitu ide-ide Thich Nhat Hanh tentang praktik hidup berkesadaran, dan konsep perkembangan anak usia dini. Konteks di sini dimaknai sebagai relasi antarteks dengan memasukkan semua situasi yang terkait dengan hal-hal di luar teks, namun mempengaruhi pemakaian bahasa. Konteks kajian ini meliputi penyusun teks, situasi teks dibuat, fungsi teks dalam kerangka tujuan tertentu tentang materi praktik hidup berkesadaran dan konsep perkembangan anak usia dini. Wacana (discourse) pada kajian ini bermaksud mensintesis atau mengungkap 
pemahaman teks dan konteks, baik yang tersembunyi maupun jelas tergambar dari materi praktik hidup berkesadaran dalam penerapannya untuk anak usia dini sesuai tahap perkembangannya.

Sintesis pendahuluan mencakup upaya penggabungan secara konsisten antara temuan analisis dan sintesis, yang meliputi fakta, gagasan, konsep, pandangan, teori atau metode sebagai cara kerja dan simpulan-simpulan. Tahap ini pengkaji berupaya menata kembali hasil analisis dalam rangka menjelaskan pengertian makna harfiah dan real meaning materi praktik hidup berkesadaran dan penerapannya untuk anak usia dini, serta tahap perkembangan anak; serta unsur subjektif atau bias yang terkandung dalam materi tersebut. Sintesis tahap lanjutan berkenaan dengan upaya penggabungan hasil pembandingan atau penyelarasan teks dengan pasti dan rinci, serta pembuktian hubungan sebab-akibat tentang materi praktik hidup berkesadaran dan penerapannya untuk anak usia dini, serta tahap perkembangan anak. Tahap sintesis akhir (final synthesis) kajian ini menggunakan teknik koligasi (interpretasi) yang mencakup usaha penggabungan bagian-bagian secara keseluruhan objek materi praktik hidup berkesadaran dan penerapannya untuk anak usia dini, serta tahap perkembangan anak yang telah dianalisis.

Keabsahan kajian menggunakan uji konfirmabilitas yang mencerminkan objektivitas kajian (Sugiyono, 2007: 121). Objektivitas kajian dilakukan dengan cara menguji hasil kajian praktik hidup berkesadaran untuk anak usia dini yang dikaitkan dengan proses yang dilakukan. Pemenuhan unsur konfirmabilitas dinyatakan dengan hasil kajian sebagai fungsi proses kajian yang memberikan jaminan terhadap confirmability standard.

\section{Hasil dan Pembahasan}

Praktik hidup berkesadaran pada anak usia ini selaras dengan aspek perkembangan moral anak karena saling berkaitan erat dalam proses integrasinya. Hasil identifikasi konsep praktik hidup berkesadaran yang digagas oleh Thich Nhat Hanh dan tahap perkembangan moral pada anak usia dini menurut Kohlberg dapat dilihat pada tabel berikut. 
Tabel 2

Identifikasi Konsep

\begin{tabular}{|l|l|}
\hline \multicolumn{1}{|c|}{$\begin{array}{c}\text { Praktik Hidup } \\
\text { Berkesadaran }\end{array}$} & \multicolumn{1}{c|}{ Perkembangan Moral Anak Usia Dini } \\
\hline Living together & Orientasi terhadap kepatuhan dan hukum \\
\hline Breathing & Relativistic hedonism \\
\hline Sitting meditation & Orientasi mengenai anak yang baik \\
\cline { 1 - 1 } Eating together & Mempertahankan norma-norma sosial dan otoritas \\
\cline { 1 - 1 } Resting & Orientasi pada perjanjian dirinya dengan lingkungan sosial \\
\cline { 1 - 1 } Noble silence & Prinsip universal \\
\cline { 1 - 1 } Hugging meditation & \\
\cline { 1 - 1 } Tea meditation & \\
\cline { 1 - 1 } Taking refuge & \\
\cline { 1 - 1 } Taking care of anger & \\
\cline { 1 - 1 } Coming home &
\end{tabular}

Komponen analisis kajian ini menghasilkan poin-poin penting yang dapat dikelompokkan menjadi tiga unsur (teks, konteks, dan wacana). Keterkaitan teks, konteks, dan wacana menjadi satu kesatuan yang menghasilkan pemahaman terhadap proses mengenai konsep praktik hidup berkesadaran dan perkembangan moral anak. Urutan unsur teks, konteks, dan wacana kedua konsep tersebut sebagaimana dapat dilihat pada tabel berikut.

Tabel 3

Teks, Konteks, dan Wacana Konsep

\begin{tabular}{|l|l|}
\hline Teks & $\begin{array}{l}\text { - Konsep praktik hidup berkesadaran dan tahap } \\
\text { perkembangan moral pada anak usia dini } \\
\text { - Citra konsep praktik hidup berkesadaran dan } \\
\text { perkembangan moral anak usia dini }\end{array}$ \\
\hline Konteks & $\begin{array}{l}\text { - Situasi di luar konsep hidup berkesadaran dan } \\
\text { perkembangan moral anak usia dini }\end{array}$ \\
& $\begin{array}{l}\text { - Penyusun konsep hidup berkesadaran dan perkembangan } \\
\text { moral anak usia dini }\end{array}$ \\
& - Fungsi hidup berkesadaran dan perkembangan moral anak \\
& usia dini \\
\hline Wacana & - Sintesis teks dan konteks \\
& - Pemahaman teks dan konteks \\
\hline
\end{tabular}

Analisis terhadap konsep praktik hidup berkesadaran dan perkembangan moral anak berdasarkan teks, konteks, dan wacana kemudian dilanjutkan dengan proses analisis synthesis checklist sesuai dengan tahapan yaitu pendahuluan, lanjutan, dan akhir. Analisis synthesis checklist 
memberikan gambaran secara mendalam mengenai proses pengambilan kesimpulan berdasarkan unsur-unsur pembentuk konsep praktik hidup berkesadaran dan perkembangan moral anak. Hasil kajian berdasarkan proses analisis dengan menggunakan synthesis checklist dapat dilihat pada tabel berikut.

Tabel 4

Proses Synthesis Checklist

\begin{tabular}{|l|l|}
\hline Pendahuluan & - Penggabungan konsep praktik hidup berkesadaran dan \\
& perkembangan moral anak usia dini \\
& - Penataan kembali hasil analisis \\
& - Menjelaskan makna harfiah dan real meaning \\
& - Subjektivitas/bias konsep hidup berkesadaran dan \\
& perkembangan moral anak usia dini \\
\hline Lanjutan & - Upaya penggabungan hasil pembandingan dengan pasti \\
& dan rinci tentang konsep praktik hidup berkesadaran dan \\
& perkembangan moral anak usia dini \\
& - Pembuktian hubungan sebab-akibat antarkonsep praktik \\
& hidup berkesadaran dan perkembangan moral anak usia \\
& dini \\
\hline Akhir & - Interpretasi (koligasi) \\
& - Usaha penggabungan hasil analisis bagian-bagian \\
& antarkonsep praktik hidup berkesadaran dan \\
& perkembangan moral anak usia dini secara keseluruhan \\
\hline
\end{tabular}

Pada dasarnya, penggabungan konsep praktik hidup berkesadaran dan perkembangan moral anak usia dini mengarah pada upaya pembentukan dan berkembangnya moral yang mengarah pada karakter anak di masa mendatang. Pembentukan karakter pada anak usia dini melibatkan pengetahuan baik yang perlu diajarkan (moral knowing), aspek emosi yang menggunakan perasaan sebagai dasar untuk bertindak sesuai dengan prinsipprinsip moral (moral feeling), dan membawa pengetahuan moral menjadi tindakan nyata (moral action) (Thomas Lickona dalam Agus Wibowo \& Gunawan, 2015: 9). Moral knowing merupakan pengetahuan moral yang perlu diajarkan kepada anak-anak, meliputi: moral awareness, knowing moral values, perspective taking, moral reasoning, decision making, dan self-knowledge. Moral feeling merupakan aspek perasaan yang harus ditumbuhkan dalam diri anak untuk bertindak sesuai dengan prinsip-prinsip moral, meliputi conscience, selfesteem, empathy, loving the good, self-control, dan humility. Moral action merupakan wujud tindakan nyata sebagai dampak dari pengetahuan moral 
yang ada dalam diri anak. Hubungan antara moral knowing, moral feeling, dan moral action menjadi dasar pembentukan karakter yang dibentuk dalam diri anak. Hasil penggabungan konsep praktik hidup berkesadaran dan perkembangan moral anak usia dini yang mengarah pembentukan karakter anak dapat dilihat pada tabel berikut.

Tabel 5

Integrasi Praktik Hidup Berkesadaran pada Perkembangan Moral Anak dan Pembentukan Karakter

\begin{tabular}{|c|c|c|c|}
\hline Perkembangan Moral & $\begin{array}{l}\text { Praktik Hidup } \\
\text { Berkesadaran }\end{array}$ & \multicolumn{2}{|c|}{ Pembentukan Karakter } \\
\hline \multirow{3}{*}{$\begin{array}{l}\text { Orientasi terhadap } \\
\text { kepatuhan dan } \\
\text { hukum }\end{array}$} & \multirow[t]{3}{*}{ Coming home } & Moral knowing & Sadar, tahu \\
\hline & & Moral feeling & Kontrol diri \\
\hline & & Moral action & Ingin, kebiasaan \\
\hline \multirow[t]{3}{*}{ Relativistic hedonism } & \multirow[t]{3}{*}{ Resting } & Moral knowing & $\begin{array}{l}\text { Alasan moral, tahu } \\
\text { diri }\end{array}$ \\
\hline & & Moral feeling & Empati \\
\hline & & Moral action & Keinginan \\
\hline \multirow[t]{3}{*}{$\begin{array}{l}\text { Orientasi mengenai } \\
\text { anak yang baik }\end{array}$} & \multirow{3}{*}{$\begin{array}{l}\text { Sitting meditation } \\
\text { Noble silence } \\
\text { Hugging } \\
\quad \text { meditation }\end{array}$} & Moral knowing & $\begin{array}{l}\text { Sadar, keputusan, } \\
\text { tahu }\end{array}$ \\
\hline & & Moral feeling & Mencintai kebenaran \\
\hline & & Moral action & Kompeten, kebiasaan \\
\hline \multirow{3}{*}{$\begin{array}{l}\text { Mempertahankan } \\
\text { norma-norma sosial } \\
\text { dan otoritas }\end{array}$} & \multirow{3}{*}{$\begin{array}{l}\text { Eating together } \\
\text { Tea meditation }\end{array}$} & Moral knowing & Perspektif \\
\hline & & Moral feeling & Empati, rendah hati \\
\hline & & Moral action & Kebiasaan \\
\hline \multirow{3}{*}{$\begin{array}{l}\text { Orientasi pada } \\
\text { perjanjian dirinya } \\
\text { dengan lingkungan } \\
\text { sosial }\end{array}$} & \multirow{3}{*}{$\begin{array}{l}\text { Taking refuge } \\
\text { Taking care of } \\
\text { anger }\end{array}$} & Moral knowing & Alasan moral \\
\hline & & Moral feeling & Empati, rendah hati \\
\hline & & Moral action & Ingin, kebiasaan \\
\hline \multirow[t]{3}{*}{ Prinsip universal } & \multirow{3}{*}{$\begin{array}{l}\text { Living together } \\
\text { Breathing }\end{array}$} & Moral knowing & Sadar, tahu, tahu diri \\
\hline & & Moral feeling & Empati, kontrol diri \\
\hline & & Moral action & Ingin, kebiasaan \\
\hline
\end{tabular}

Coming home merupakan bentuk praktik hidup berkesadaran yang melihat bahwa saat kembali ke rumah adalah saat berkumpul dengan keluarga dan masyarakat. Secara filosofis, coming home bermakna kembali pada latihan dan pernapasan. Setiap individu sebagai bagian dari masyarakatnya harus berusaha menumbuhkan keselarasan dalam keluarga dan masyarakat. Perkembangan moral anak tahap orientasi terhadap kepatuhan dan hukum memiliki ciri patuh pada hukum yang ditetapkan. Anak usia dini mendapatkan pengajaran berharga dari lingkungan keluarga. Peran dan posisi anak usia dini sebaiknya dikenalkan sejak kecil agar memiliki tanggung jawab terhadap keluarga. Jika anak pergi bermain 
hendaknya diingatkan untuk pulang pada waktu yang telah disepakati. Dengan kata lain, anak memiliki karakter tanggung jawab untuk kembali ke rumah dengan penuh kesadaran sendiri. Anak yang mengetahui perannya sebagai bagian dari anggota keluarga akan sadar dan tahu melalui pemahaman yang dimilikinya untuk kemudian digunakan mengontrol dirinya dari keinginan menentang aturan orangtua. Jika hal ini dilakukan secara konsisten, maka akan menjadi kebiasaan yang menjadi ciri khas karakter unik dari anak tersebut.

Relativistic hedonism merupakan tahap kedua tingkat prakonvensional perkembangan moral setelah tahap pertama orientasi terhadap kepatuhan dan hukuman. Tahap ini memiliki ciri adanya faktor pribadi yang relatif dan prinsip kesenangan. Anak usia dini memandang dirinya sendiri sesuai dengan prinsip kesenangan yang dimilikinya. Praktik hidup kesadaran resting didasarkan pada pengetahuan anak tentang kapan waktu beristirahat yang tepat. Seni beristirahat yang baik dari segala aktivitas yang dilakukan anak akan memberikan akibat yang sesuai dengan fungsi istirahat itu sendiri. Istirahat memberikan efek relaksasi yang dapat menjaga tubuh agar dapat memulihkan diri. Kebutuhan akan istirahat menghendaki adanya alasan moral di baliknya. Anak yang memiliki alasan moral baik dalam melakukan istirahat akan tahu diri, berempati kepada sekitarnya yang juga memerlukan istirahat, dan membutuhkan keinginan yang kuat untuk mewujudkannya.

Sitting meditation, noble silence, dan hugging meditation merupakan praktik hidup berkesadaran yang bertujuan untuk melatih perhatian dan ketenangan pada diri anak. Meditasi duduk, diam mulia, dan meditasi peluk mampu melihat ke dalam diri anak, mengenal diri, dan menunjukkan kepedulian terhadap sesamanya. Pengenalan terhadap nilai diri dan munculnya kepedulian pada anak merupakan perkembangan moral yang berorientasi pada pribadi sebagai anak yang baik. Praktik hidup berkesadaran sitting meditation, noble silence, dan hugging meditation berorientasi pada pembentukan pribadi anak yang baik untuk membentuk karakter kuat pada diri anak. Komponen karakter moral knowing mengandung unsur kesadaran, keputusan, dan pengetahuan pada diri anak untuk memahami konsep meditasi duduk, diam mulia, dan meditasi peluk. Komponen karakter moral 
feeling memiliki ciri mencintai kebenaran pada segala aktivitas anak. Anak yang mencintai kebenaran memiliki kehalusan budi dan sifat antikekerasan pada segala aktivitas keseharian. Jika anak konsisten melakukan hal ini, maka akan menjadi berkompeten dan memiliki kebiasaan yang konsisten. Strategi pembelajaran untuk anak usia dini lebih tepat menggunakan pendekatan pembiasaan untuk mendisiplinkan anak. Komponen karakter moral action mencakup ciri kebiasaan dalam proses pembentukannya.

Aspek perkembangan moral anak pada tahap mempertahankan normanorma sosial dan otoritas memiliki ciri menyadari kewajibannya untuk ikut melaksanakan norma-norma yang ada dan mempertahankannya. Praktik hidup berkesadaran yang selaras dengan tahap ini adalah eating together dan tea meditation. Melalui kegiatan makan dan minum teh bersama, anak belajar bagaimana norma yang berlaku di masyarakat dan kesesuaian dengan dirinya. Anak memiliki sudut pandang tentang aktivitas makan dan minum maupun proses ketersediaan makanan dan minuman merupakan proses panjang yang melibatkan kebaikan banyak pihak hingga ke meja makan. Hal ini juga dapat menimbulkan sikap empati dan rendah hati serta rasa syukur dan terima kasih kepada semua pihak yang terlibat dalam penyediaan makanan dan minuman. Anak usia dini memiliki keinginan untuk makan dan minum secara alami sesuai dengan kebutuhan tubuhnya. Namun demikian, kegiatan sederhana makan dan minum dapat digunakan sebagai sarana untuk pembelajaran moral dan nilai anak menuju pengembangan karakter yang baik. Aktivitas makan dan minum dengan mengikuti norma yang sesuai disertai dengan perhatian penuh akan membawa kebiasaan baik pada anak. Kebiasaan baik ini akan terbawa terus hingga anak menjadi dewasa kelak.

Taking refuge dan taking care of anger merupakan bentuk praktik hidup berkesadaran yang selaras dengan aspek perkembangan moral anak pada orientasi perjanjian dirinya dengan lingkungan sosial. Tekad dalam doa yang dilakukan anak-anak akan memberikan suasana perlindungan dan keterbukaan dengan dasar pengakuan atas keadaan dirinya. Hubungan vertikal yang bersifat spiritual membawa anak pada usaha untuk melaksanakan bentuk-bentuk kebaikan yang mengarah pada pembentukan karakter yang baik. Hubungan sosial anak dapat dilakukan melalui bentuk 
praktik hidup berkesadaran taking care of anger (mengelola kemarahan). Kemarahan anak muncul seiring dengan terganggunya diri akibat sesuatu dari lingkungan sekitarnya. Jika anak mampu mengelola kemarahannya, maka akan berdampak pada lingkungannya. Jika anak mampu mengendalikan dirinya sendiri, maka secara otomatis anak tersebut tidak membuat peluang orang lain di sekitarnya untuk membalasnya dengan kemarahan. Anak yang mampu mengendalikan diri dari kemarahan akan membuat suasana lingkungan sosialnya menjadi harmoni. Tekad kuat dalam doa dan mengelola kemarahan merupakan bentuk praktik hidup berkesadaran yang mengarah pada pembentukan karakter dengan diawali pemahaman bahwa anak mengetahui alasan moral mengapa anak melakukannya (moral knowing), lalu dengan rendah hati dan empati sadar bahwa apa yang dilakukannya akan berdampak pada lingkungan sosialnya (moral feeling), kemudian hal tersebut ingin dilakukan secara konsisten agar menjadi kebiasaan (moral action).

Prinsip universal pada tahap aspek perkembangan moral anak memiliki ciri berkembangnya norma etik untuk menentukan perbuatan moral. Kesadaran dan pemahaman anak mengenai prinsip ini dapat diterapkan melalui praktik hidup berkesadaran living together dan breathing. Kesadaran hubungan dalam hidup bersama dengan bernapas di alam yang sama membawa pemahaman bahwa hidup harus saling menghargai dalam kemarmonian. Hal ini mendorong sikap anak untuk selalu berempati dan mengontrol dirinya dalam melakukan hubungan sosial dengan lingkungan sekitar. Empati dan kontrol diri sebagai moral action dalam pembentukan karakter menjadi kebiasaan anak dalam pengembangan moralnya. Jika praktik hidup berkesadaran living together dan breathing dilatih sejak dini dengan pemahaman yang benar, maka akan menghasilkan karakter-karakter baik lainnya yang penting dimiliki anak dalam menjalin hubungan dengan sesamanya.

\section{Kesimpulan}

Berdasarkan pada pembahasan dan analisis mendalam di atas, dapat disimpulkan bahwa: (a) bentuk praktik kesadaran yang dapat diterapkan 
pada anak usia dini yaitu: living together, breathing, sitting meditation, eating together, resting, noble silence, hugging meditation, tea meditation, taking refuge, taking care of anger, dan coming home; (b) integrasi praktik hidup berkesadaran untuk perkembangan moral meliputi: orientasi terhadap kepatuhan dan hukuman (coming home), relativistic hedonism (resting), orientasi mengenai anak yang baik (sitting meditation, noble silence, hugging meditation), mempertahankan norma-norma sosial dan otoritas (eating together, tea meditation), orientasi pada perjanjian dirinya dengan lingkungan sosial (taking refuge, taking care of anger), dan prinsip universal (living together, breathing); dan (c) integrasi bentuk praktik hidup berkesadaran masing-masing dapat mengarah pada pembentukan karakter yang mencakup tiga komponen, yaitu moral knowing (sadar, tahu, alasan moral, tahu diri, keputusan, perspektif), moral feeling (kontrol diri, empati, mencintai kebenaran, rendah hati), dan moral action (ingin, kebiasaan, kompeten).

Penerapan praktik hidup berkesadaran yang mengarah pada tahap perkembangan moral anak sejalan dengan upaya pembentukan karakter. Praktik ini dapat dijadikan program oleh guru-guru mata pelajaran pendidikan agama Buddha maupun agama lainnya untuk memberikan jaminan pada pemenuhan aspek perkembangan nilai moral dan agama. Penerapan praktik hidup berkesadaran pada anak usia dini dilakukan dengan memperhatikan penyelenggaraan pendidikan yang diprogramkan, baik dari sisi komponen tujuan, materi, metode, media, dan evaluasi.

\section{Daftar Pustaka}

Agus Wibowo \& Gunawan. 2015. Pendidikan Karakter Berbasis Kearifan Lokal di Sekolah. Yogyakarta: Pustaka Pelajar.

Adinto F. Susanto (ed.). 2017. Mindfulness for Success. Jakarta: Grasindo.

Cyrus T. Lalompoh \& Kartini Ester Lalompoh. 2017. Metode Pengembangan Moral dan Nilai-Nilai Keagamaan Bagi Anak Usia Dini. Jakarta: Grasindo.

Hanh, Thich Nhat. 2016. Menabur Benih: Praktik Hidup Berkesadaran Bersama Anak-Anak. Terjemahan Dharma Kesuma. Jakarta: Karaniya.

Mestika Zed. 2008. Metode Penelitian Kepustakaan. Jakarta: Yayasan Obor Indonesia. 
Smith, Sue Erica. 2013. Buddhist Voices in School: How a Community Created a Buddhist Education Program for State Schools. Rotterdam, The Netherlands: Sense Publishers.

Sugiyono. 2007. Memahami Penelitian Kualitatif. Bandung: Penerbit Alfabeta.

http://thichnhathanhfoundation.org/be-mindful-in-daily-life/, diakses tanggal 13 Oktober 2017.

https://nasional.tempo.co/read/846217/cegah-anak-anak-terpaparradikalisme-kpai-gandeng-bnpt, diakses tanggal 12 Oktober 2017. 